\title{
Negative impacts of long working hours: a comparative study among nurses
}

\begin{abstract}
This survey based descriptive research has been undertaken in Tirunelveli city, Tamilnadu with the objectives of understanding and differentiating perception of nurses working in both multi-speciality and single speciality hospitals towards various factors associated with longer working hours and negative impacts of longer working hours on health, family life and social life. The study has sampled 120nurses(60 from multi-speciality hospitals and 60 from single speciality hospitals) qualified with Bachelor of Science in Nursing and Diploma in General Nursing and Midwifery (DGNM) from private multi-speciality hospitals using judgement sampling technique. Primary data have been collected using structured self-made questionnaire. Secondary data have been collected from journals, books and websites. The result of the study shows that perception of nurses working in both kinds of hospitals are same towards impact of longer working hours on their health, family and social life.
\end{abstract}

Keywords: long working hours, nurse, health, family life, social life, multispeciality hospitals, single speciality hospitals, tirunelveli city
Volume I Issue 2 - 2017

\author{
Rajan D \\ Department of Business Administration, Blue Crest College, \\ Ghana \\ Correspondence: Rajan D, Department of Business \\ Administration, Blue Crest College, Accra, Ghana. \\ Emaildrdirajan@gmail.com
}

Received: July 01, 2017 | Published: September 18, 2017

\section{Introduction}

\section{Background of the study}

Strong physical and mental health is important for all employees irrespective of level of management. From top level management to low level management, people wish to have both strong physical and mental health in order to enjoy family as well as work life happily and satisfactorily. In this high technology and competitive business world, the organizations intend to retain customers with them to enhance competitive advantage. In order to achieve and maintain competitive advantage strong manpower with rich experience is needed. But, at the same time, the employee turnover ratio also is equally taking place according to the speed in which new employee is recruited. Job dissatisfaction is one of the primary reasons for high employee turnover among all kinds of employees.

Though various factors such as motivating leadership style, adequate salary, pleasant working conditions, rich welfare facilities, strong training and development policy, reward and recreation system, normal working hours remain major factors which stands before all other factors since it decides not only physical life of the employees, but also it decides mental health and family and work life balance of the employees.

Nominal working hours i.e., 8hours or 6hours working will make employees productive and make them to concentrate balancing both family and work life by devoting adequate time for family and social life. But, when working hours is longer it will not only make the employees dissatisfied with work but also make employees less productive and deteriorate their physical and them to quit the job. The high employee turnover will impact organization's reputation negatively. Moreover, cost of recruitment, training will also increase. As far as nursing profession is concerned as they are dealing with patients' life, their physical and mental health is very important. Long working hours will distract their attention which will further affect safety of the patients. Hence, long working hours not only affect physical, mental health, family and social life of employees but also affect patients' safety and organization reputation. Therefore, it is essential for hospital management to know how far long working hours impact employees' physical, mental health family and social life and take corrective measures to regulate working hours.

The study area, Tirunelveli city has grown significantly in the past few years in field of health care. Many hospitals, laboratories and pharmaceuticals have been established newly and their growth is abundant. But, still in many hospitals and diagnostic centres twelve hours working with two shift working system is in practice. Moreover, in the study area, human resource management practice is poor in both multi-speciality and single speciality hospitals. Inadequate salary, incentives, unfair increment, promotion, discrimination on the basis of caste, religion and locality, poor welfare facilities and absence of training and development programmes are apparently seen in most of the hospitals. When twelve hours working pattern which affect health, family life and social life, join with these weak human resource management system, it will definitely affect health of the employees severely. Hence, this present research is strongly needed to undertake in the study to know about negative impacts of longer working hours on health, family life and social life of the nurses working in both multi-speciality and single speciality hospitals.

\section{Need for the study}

Labour law insists eight hours duty should be followed in all kinds of organization. But in many organizations, this law is not strictly followed. The corruption existing at all levels is the primary reason. Most of the organizations in large cities are strictly following the rules said in the labour act. But, the organization in second tier cities like Tirunelveli, do not follow working hours very strictly. Hence, they have twelve hours duty with two shift system instead of eight hours with three shift system. Financial need, marital status, unemployment status, children's' education push the employees to accept twelve hours working and continue their job. In addition to twelve hours duty 
which is the major threatening factors of the life of the employees affecting health, family and social life of the employees, there are many other factors which are associated with working hours paralysing the employees' health, family and social life. Transport problem, long standing in the bus stand for bus, safety problem, biased shift schedule, biased leadership style of the superiors, low salary, poor increment and absence of career growth opportunities are some of the other factors impacting female employees severely. As far as nursing profession is concerned, most of the nurses in Tirunelveli city come from village areas and they are unmarried and also they are staying in the hostels.

Most of the hospitals, do not have attached cafeterias. They take food from the hotels that are not hygienic in nature. Some of the hospitals have attached cafeteria but they food provided is not sufficient to work for twelve hours. Their nature of work also involves long standing and close observation towards patients. When they need to work for longer working with long working hours it will definitely affect their health. Moreover, when the employees need to work for longer hours for prolonged period of time, it will also affect their family and social life. Hence, it is needed to make them awareness how longer working hours affect their health, family life and social life and how to cope up with longer working hours to balance both family and work life and how to safeguard their health. Therefore, this present study is undertaken in the study area.

\section{Scope of the study}

The present research has focused nurses qualified with B.Sc Nursing and Diploma in General nursing and Midwifery (DGNM) who are working in private multi-speciality hospitals and single speciality hospitals in Tirunelveli city, Tamilnadu.

\section{Significance of the study}

The present research gives ample opportunities for hospital management and other similar organizations which have employed nurses to take initiative steps towards regulating working hours by assisting them establish to create new policies or make changes in their existing policy with regard to long working hours. This study will also be useful for the nurses to grow their knowledge about various negative impacts associated with longer working hours and how to overcome those negative impacts by self-management. This study will be serving as a source of secondary data for future research scholars.

\section{Objectives of the study}

The objectives of the study are as follows.

a. To understand and differentiate perception of nurses towards factors associated with long working hours.

b. To know and differentiate perception of nurses towards various negative impacts of long working hours on health, family and social life.

c. To offer suitable suggestions to overcome negative impacts of longer working hours

\section{Limitations of the study}

The present research has confined to Tirunelveli city only. It has not focused the entire district. The study has focused nurses working in multi-speciality and single speciality hospitals and it has not focused the nurses working in government hospitals and diagnostic centres. The present study has focused nurses qualified with Bachelor of Science in Nursing and Diploma in General nursing and Midwifery and it has not focused nursing assistants who are qualified with Diploma in Nursing Assistant (DNA) and Female Nursing Assistant (FNA). Moreover, the present research has focused negative impacts of long working hours only. It has not explored any other factors such as shift work, salary and welfare facilities and so on. As a result of these limitations, there is a need of caution to generalize the result of this study to other category of occupational groups and other kinds of hospitals such as government and diagnostic centres.

\section{Review of literature}

Rajan D et al. ${ }^{1}$ in his study negative impact of long working hours among nurses found that too long and unsocial working hours, rigid rules of the hospital with regard to working hours, inability to leave the duty on time and inability to leave the duty on time were the top most factors perceived as factors associated with long working hours. Health related issues, destructive behaviour at work, inability to balance both work and family life and dissatisfaction in relationship with life partner and inability to satisfy needs were the topmost negative impacts of long working hours on the nurses. Rosner $\mathrm{C}$ et al. ${ }^{2}$ in her study working long hours is bad for women's health found that women who worked more than 60 hours per week were nearly 3 times more likely to develop heart diseases, non - skin cancers, arthritis and diabetes than those who worked less. The study found no difference in the risk of chronic lung disease, asthma, depression or high blood pressure based on work hours. People who work long hours typically have less free time to engage in health behaviour like exercise. It is definitely more of a problem for women. ${ }^{3}$ explored the relationship and impact of working hours on work-family conflict and social support among doctors and proved that working longer hours lead to higher work - family conflict and lower social support i.e. work hours significantly contribute to work - family conflict and social support. Study also revealed that in the long run working hours lead to severe health problem further affecting personal and social relationship.

Caruso CC et al. ${ }^{4}$ studied negative impacts of shift work and long working hours and reported that shift work and long working hours increase risk for reduced performance on the job, obesity, injuries and wide range of chronic diseases. The study found that sleeplessness was the serious issue of the long working hours. Akhtar S et al. ${ }^{5}$ examined impact of long working hours on family well being of corporate family. The study analysed long working hours under four dimensions namely physiological and behavioural effects, work life balance, work stressors and inflexible schedules. Family well being was analysed under three dimensions namely destructive family, inter-role conflict and reduced quality of life. The result of the study proved that the factors work life balance and work stressors had significant impact on the well being of the family where as inflexible work schedule did not have significant impact.

Rajan \& Velanganni et al. ${ }^{6}$ examined stress and coping strategies of nurses working in private multi-speciality hospitals in Tirunelveli city. The study found that unclear role, inadequate salary and inadequate increment and incentives were the foremost organization-related stressors. Too long working hours, shift work and over workload along with paper work were the foremost nurses specific stressors. The study also indicated that stress-affected job satisfaction of nurses. The result of the study regarding coping strategies described that praying, 
asking advice from a relative or friend respected and turning to work on another activity to take the mind off things are the foremost coping being followed by the nurses. Thinking about how a person admired will handle this situation and use that as a model and trying to get away from it for a while by resting or taking a vacation are the next foremost coping style being followed by the nurses. Maintaining pride and keeping a stiff upper lip and knowing what have to be done, and to double the efforts to make things work and taking it out on other people are the least coping being followed by the nurses. Crew S et al. ${ }^{7}$ studied qualitative study on effects of working unsocial hours. The study analysed both positive results and negative results of working unsocial hours.

The positive result of unsocial working hour was pay. The negative results of unsocial working hour were lack of sleep, mouth ulcers and gastro intestinal upset and increased risk of cardiovascular disease. Verite et al. ${ }^{8}$ analysed excessive overtime in Chinese supplier factories and proved that workers are working theses significant overtime hours primarily for financial reasons. The study reported that fatigue and exhaustion, sadness and depression were correlated with long working hours. Common ailments attributed to excessive overtime were eye strain and back pains. Westen $\mathrm{R}$ et al..$^{9}$ analysed the impact of long working hours on employed fathers and their families. The result of the study showed that dissatisfaction with overall job dissatisfaction with relationship with partner, dissatisfaction with overall life, parenting stress, work and family imbalance, negative effect on general health, vitality and mental health. Qureshi MS et al. ${ }^{10}$ studied impacts of late working hours on employees' performance of engineers in Telecom company of Pakistan and proved that overworking not only damaging the performance of these employee but also cause health issues such as sleep inertia, fatigue and lack of innovative solution to their daily work. Study also revealed that higher percentage of employees who work for long hours were more involved in unethical activities, e.g., misuse of organizational assets, authority, sexual harassment and breaching code of conduct of organization. Interview with respondent revealed that overworking and less salary ignite them to indulge in unethical activities when they are working for long years.

It could be understood from literatures reviewed, that few research works have been undertaken in the study area about work related stress, occupational hazards and negative impact of long working hours among nurses. Those studies have described how longer working hours cause work stress. The study undertaken in the study area about negative impact of long working hours has focused nurses working in multi-speciality hospitals and it has not focused nurses working in single speciality hospitals. Therefore, there is a scope to study how longer working hours affect health, family and social life of nurses working in single speciality hospitals also. Hence, the present study is undertaken in the study area as comparative study covering both multi-speciality and single speciality hospitals.

\section{Research methodology}

This survey based descriptive research work has adopted quantitative research approach. The element of this research is nurse working in private multi-speciality and single speciality hospitals in Tirunelveli city, Tamilnadu. The study has sampled 120 (60 from single speciality and 60 from multi-speciality hospitals) nurses qualified with Bachelor of Science in Nursing and Diploma in General Nursing and Midwifery using judgement sampling technique. The primary data were collected from them using self-made questionnaire.
The questionnaire had been made based on Likert's five points scale namely 'Strongly agree, Agree, No opinion, Disagree and strongly disagree'. The scales carried the values of 5, 4, 3, 2 and 1 respectively. The questionnaire consisted on three sections namely section A that talked about profile of the respondents, section B that described perception of respondents towards factors associated with long working hours and section $\mathrm{C}$ that speak about perception of the nurses towards negative impacts of long working hours on health, family life and social life. Secondary data have been collected from journals, projects and websites. Percentage analysis has been done to analyse profile of the respondents. Mean and standard deviation have been administered to understand and differentiate perception of nurses toward factors associated with long working hours and negative impacts of long working hours.

\section{Analysis and results}

It can be understood from Table 1 that among the respondents of multi-speciality hospitals, $8.33 \%$ were male and $91.67 \%$ were female. Of them, $18.33 \%$ were below 25 years of age, $43.33 \%$ between 25 and 30 years, $23.33 \%$ between 30 and 35 years and $15 \%$ were above 35 years of age. Furthermore, among them, $86.67 \%$ were married and $13.33 \%$ were unmarried. Of them, $88.33 \%$ were qualified with DGNM and $11.67 \%$ were qualified with B.Sc in Nursing. In all, $23.33 \%$ had below 2 years of work experience, $43.33 \%$ between 2 and 4years, $20 \%$ between 4 and 6years and $13.33 \%$ had above 6years of work experience. Among them, 25\% were drawing below Rs. 6000 of salary, $46.67 \%$ between Rs. 6000 and $8000,16.67 \%$ between Rs. 8000 and 10000 and $11.67 \%$ of them were drawing above Rs. 10000 of salaries. It can be known from Table 1 that among the respondents of single-speciality hospitals, $3.33 \%$ were male and $96.67 \%$ were female. Of them, $20 \%$ were below 25 years of age, $46.67 \%$ between 25 and $30 y$ years, $26.67 \%$ between 30 and $35 y$ years and $23.33 \%$ were above 35 years of age.

Furthermore, among them, $88.33 \%$ were married and $11.67 \%$ were unmarried. Of them, $98.33 \%$ were qualified with DGNM and 1.67\% was qualified with B.Sc in Nursing. In all, $16.67 \%$ had below 2years of work experience, $38.33 \%$ between 2 and 4 years, $21.67 \%$ between 4 and 6 years and $23.33 \%$ had above 6 years of work experience. Among them, $26.67 \%$ were drawing below Rs. 6000 of salary, $51.67 \%$ between Rs. 6000 and 8000, 11.67\% between Rs. 8000 and 10000 and $10 \%$ of them were drawing above Rs. 10000 of salaries. It can be understood from Table 2 that perception of nurses working in both kinds of hospitals is same and they are medium at level. It could be known from this result that nurses working in both kinds of hospitals are exposed to same problems with regard to working hours. Most of the hospitals in study area are following twelve hours duty with two shift system and the employees are not able to relieve from duty on time because most of the hospitals are located at interior place and bus facilities are not available from hospitals which makeemployees who come to duty and leave from duty undue delay. Moreover, as study area is rapidly growing heavy traffic jam is seen in most of place and most of the employees belong to village areas they need to wait in bust stop for long time because of lack of bus facilities and overcrowd in bus. Due to these reasons, most of the employees find difficult to report to duty on time and this makes employees who exist in duty delay to relieve from duty. It can be known from Table 3 that perception of respondents working in both kinds of hospitals are equal towards impact of long working hours on health of the individual. From the equality in perception of respondent working in both kinds 
of organization it could be understood that both of them have equally been affected by long working hours.

Respondents working in both kinds of hospitals have shown high perception towards tiredness, fatigue and depression and sleeplessness and diabetes and hyper tension. From the high importance towards these factors, it could be known that employees working in both kinds of organizations are suffered a lot both physically and mentally. Lot of research has proved that long working hours directly affect health and it produces diabetes mellitus, hypertension and loss of weight as long working hours cause changes in body metabolism and stress and depression which are primarily responsible for health related disorders. It could be understood from Table 4 that perception exhibited by nurses working in both kinds of organization is same towards impact of long working hours on family and social life. It could be known from equal importance given by nurses working in both kinds of organization that nurses are experiencing difficulties with their family and social life.

Long working hours indeed naturally affect work and family life of the nurses. When employees work for longer hours, naturally time they spend at home become less which will further collapse their attention they pay over life partner, children and other family members. Medically, when employee work for longer hours their body energy is sucked a lot and they cannot be concentrating in their family activities. As employees working in both kinds of organizations have given more preference towards inability to balance both work life and family life, it could be understood that they are in need of counseling and training how to manage time to balance both family and personal life. It could be understood from Table 5 that perception of respondents working in both kinds of employees towards impact of longer working hours on performance is equal. It can be known from these findings that most of the employees are facing difficulties to deliver their duties perfectly because of longer working hours.

As long working hours dramatically affect health of the employees negatively, it will affect the performance of the employees quite naturally. It will usually be exposed in the form of absenteeism, impaired interpersonal relationship, stress, developing thoughts of quitting job and lack of commitment and morale towards the organization and work. Lack of commitment and morale will cause dissatisfaction in the work and cause unsatisfactory behaviour in work place including frequent absenteeism and availing leave which will affect work flow of the department leading to worsening care given to the patients. Moreover, long working hours will cause the employees to get into workplace accident which will further affect their health and patient safety also. As much importance has been given by nurses working in both kinds of organization towards destructive behaviour it can be understood from the findings that the employees need training how to work patiently without stress. They also need counseling how to go smoothly with co-workers during emergency situations.

Table I Profile of the respondents

\begin{tabular}{|c|c|c|c|c|c|c|}
\hline \multirow{2}{*}{ S. no } & \multirow{2}{*}{ Measure } & \multirow{2}{*}{ Description } & \multicolumn{2}{|c|}{ Multi speciality hospitals } & \multicolumn{2}{|c|}{ Single speciality hospitals } \\
\hline & & & Frequency & Percentage & Frequency & Percentage \\
\hline \multirow{2}{*}{1} & \multirow{2}{*}{ Sex } & Male & 5 & 8.33 & 2 & 3.33 \\
\hline & & Female & 55 & 91.67 & 58 & 96.67 \\
\hline \multirow{4}{*}{2} & \multirow{4}{*}{ Age } & Below 25 years & 11 & 18.33 & 12 & 20 \\
\hline & & Between 25 and 30 years & 26 & 43.33 & 28 & 46.67 \\
\hline & & Between 30 and 35 years & 14 & 23.33 & 16 & 26.67 \\
\hline & & Above 35 years & 9 & 15 & 14 & 23.33 \\
\hline \multirow{2}{*}{3} & \multirow{2}{*}{ Marital Status } & Married & 52 & 86.67 & 53 & 88.33 \\
\hline & & Unmarried & 8 & 13.33 & 7 & 11.67 \\
\hline 4 & $\begin{array}{l}\text { Educational } \\
\text { Qualification }\end{array}$ & DGNM & 53 & 88.33 & 59 & 98.33 \\
\hline \multirow{4}{*}{5} & \multirow{4}{*}{$\begin{array}{l}\text { Year of working } \\
\text { experience }\end{array}$} & Below 2 year & 14 & 23.33 & 10 & 16.67 \\
\hline & & Between 2 and 4 years & 26 & 43.33 & 23 & 38.33 \\
\hline & & Between 4 and 6 years & 12 & 20 & 13 & 21.67 \\
\hline & & Above 6 years & 8 & 13.33 & 14 & 23.33 \\
\hline \multirow{4}{*}{6} & \multirow{4}{*}{ Salary } & Below 6000 & 15 & 25 & 16 & 26.67 \\
\hline & & Between 6000 and 8000 & 28 & 46.67 & 31 & 51.67 \\
\hline & & Between 8000 and 10000 & 10 & 16.67 & 7 & 11.67 \\
\hline & & Above 10000 & 7 & 11.67 & 6 & 10 \\
\hline
\end{tabular}

Source, Primary data 
Table 2 Perception towards factors associated with long working hours

\begin{tabular}{|c|c|c|c|c|c|c|c|c|c|c|}
\hline \multirow{3}{*}{$\begin{array}{l}\text { Factors associated with } \\
\text { long working hour }\end{array}$} & \multicolumn{5}{|c|}{$\begin{array}{l}\text { Multi speciality } \\
\text { hospitals }\end{array}$} & \multicolumn{5}{|c|}{ Single speciality hospitals } \\
\hline & \multirow[b]{2}{*}{ Mean } & \multirow[b]{2}{*}{ SD } & \multicolumn{3}{|c|}{ Extent of perception } & \multirow{2}{*}{ Mean } & \multirow[b]{2}{*}{ SD } & \multicolumn{3}{|c|}{ Extent of perception } \\
\hline & & & Low & Medium & High & & & Low & Medium & High \\
\hline $\begin{array}{l}\text { Too long and unsocial } \\
\text { working hours }\end{array}$ & 25.66 & 4.69 & 18.33 & 65.33 & 14.33 & 25.62 & 4.57 & 15.67 & 66.33 & 18 \\
\hline $\begin{array}{l}\text { Rigid rules of the hospital } \\
\text { with regard to working } \\
\text { hours (e.g. compelling to } \\
\text { come to the duty on time } \\
\text { in the morning even if the } \\
\text { nurses leave } \\
\text { lately in the previous day) }\end{array}$ & 25.55 & 4.81 & 15 & 69 & 16 & 25.46 & 4.78 & 16 & 61.33 & 22.67 \\
\hline $\begin{array}{l}\text { Inability to leave the duty } \\
\text { on time because of more } \\
\text { number of patients } \\
\text { and too much work load }\end{array}$ & 25.48 & 4.52 & 16.67 & 69 & 14.33 & 25.43 & 4.28 & 19 & 63.67 & 17.33 \\
\hline $\begin{array}{l}\text { Inability to leave the duty } \\
\text { on time because of late } \\
\text { arrival of reliever }\end{array}$ & 24.66 & 3.15 & 16 & 70 & 14 & 24.56 & 3.08 & 10.67 & 70 & 19.33 \\
\hline $\begin{array}{l}\text { Arrival of patients at the } \\
\text { time of leaving duty that } \\
\text { will enhance working time }\end{array}$ & 23.03 & 4.71 & 19.33 & 65 & 15.67 & 22.97 & 4.56 & 19 & 68.33 & 12.67 \\
\hline $\begin{array}{l}\text { Inadequate rest hours in } \\
\text { duty and need to stand for } \\
\text { longer time in the } \\
\text { department }\end{array}$ & 22.06 & 2.19 & 19.33 & 66.33 & 14.33 & 22.03 & 2.17 & 18.33 & 72 & 9.67 \\
\hline $\begin{array}{l}\text { Waiting for longer time } \\
\text { in bus stand for bus after } \\
\text { work }\end{array}$ & 21.73 & 4.94 & 20 & 66.33 & 13.67 & 21.68 & 3.75 & 15.67 & 68.33 & 16 \\
\hline $\begin{array}{l}\text { High traffic disturbance } \\
\text { which cause undue delay } \\
\text { to reach home }\end{array}$ & 21.68 & 6.01 & 11.67 & 69 & 19.33 & 20.54 & 3.56 & 20.67 & 56 & 23.33 \\
\hline $\begin{array}{l}\text { Longer distance between } \\
\text { hospital and bus stand and } \\
\text { need to walk to reach } \\
\text { the spot }\end{array}$ & 21.51 & 4.83 & 17.67 & 66.67 & 15.67 & 21.23 & 3.43 & 19 & 60.67 & 20.33 \\
\hline
\end{tabular}

Source, Primary data, 2017 
Table 3 Perception towards impact of long working hours on health

\begin{tabular}{|c|c|c|c|c|c|c|c|c|c|c|}
\hline \multirow{3}{*}{ Health } & \multicolumn{5}{|c|}{ Multi speciality hospitals } & \multicolumn{5}{|c|}{ Single speciality hospitals } \\
\hline & \multirow{2}{*}{ Mean } & \multirow{2}{*}{ SD } & \multicolumn{3}{|c|}{ Extent of perception } & \multirow{2}{*}{ Mean } & \multirow{2}{*}{ SD } & \multicolumn{2}{|c|}{$\begin{array}{l}\text { Extent of } \\
\text { perception }\end{array}$} & \multirow[b]{2}{*}{ High } \\
\hline & & & Low & Medium & High & & & Low & Medium & \\
\hline $\begin{array}{l}\text { Tiredness, fatigue and } \\
\text { depression }\end{array}$ & 24.39 & 3.55 & 16.67 & 66.33 & 17 & 24.13 & 3.28 & 17.33 & 66.33 & 14.33 \\
\hline $\begin{array}{l}\text { Sleeplessness, lack of sound } \\
\text { sleep and inability to wake } \\
\text { up from bed }\end{array}$ & 24.12 & 3.58 & 17 & 60.33 & 22.67 & 14.08 & 2.28 & 14 & 69 & 17 \\
\hline $\begin{array}{l}\text { Diabetes mellitus and hyper } \\
\text { tension }\end{array}$ & 23.16 & 3.15 & 20 & 61.67 & 18.33 & 23.71 & 3.01 & 15.67 & 70 & 14.33 \\
\hline $\begin{array}{l}\text { Constipation and duodenal } \\
\text { ulcer }\end{array}$ & 23.13 & 3.11 & 11.67 & 69 & 19.33 & 23.11 & 3.09 & 15 & 72 & $\begin{array}{l}13 \\
15.67\end{array}$ \\
\hline Loss of weight & 22.05 & 3.08 & 20 & 67.33 & 12.67 & 22.03 & 3.05 & 18.33 & 66 & \\
\hline $\begin{array}{l}\text { Eye strain and eye related } \\
\text { problem }\end{array}$ & 21 & 3.06 & 19.33 & 70 & 10.67 & 21.97 & 3.01 & 16.67 & 69 & 14.33 \\
\hline $\begin{array}{l}\text { Pain (head ache, joint pain } \\
\text { and generalised body pain) }\end{array}$ & 21.89 & 3.01 & 19.33 & 71 & 9.67 & 21.87 & 2.97 & 18.33 & 67.33 & 14.33 \\
\hline
\end{tabular}

Source, Primary data, 2017

Table 4 Perception towards impact of long working hours on family and social life

\begin{tabular}{|c|c|c|c|c|c|c|c|c|c|c|}
\hline \multirow{3}{*}{ Family and social life } & \multicolumn{5}{|c|}{ Multi speciality hospitals } & \multicolumn{5}{|c|}{$\begin{array}{l}\text { Single speciality } \\
\text { hospitals }\end{array}$} \\
\hline & \multirow{2}{*}{ Mean } & \multirow{2}{*}{ SD } & \multicolumn{3}{|c|}{$\begin{array}{l}\text { Extent of } \\
\text { perception }\end{array}$} & \multirow{2}{*}{ Mean } & \multirow{2}{*}{ SD } & \multicolumn{3}{|c|}{$\begin{array}{l}\text { Extent of } \\
\text { perception }\end{array}$} \\
\hline & & & Low & Medium & High & & & Low & Medium & High \\
\hline $\begin{array}{l}\text { Inability to balance both work and } \\
\text { family life (e.g. neglecting home } \\
\text { matters } \\
\text { and forgetfulness in the work) }\end{array}$ & 23.16 & 3.15 & 20 & 61.67 & 18.33 & 23.22 & 3.18 & 16.33 & 68.33 & 15.33 \\
\hline $\begin{array}{l}\text { Dissatisfaction in relationship with } \\
\text { life partner (conflict and dispute } \\
\text { with } \\
\text { life partner) and inability to satisfy } \\
\text { his needs }\end{array}$ & 19.39 & 3.55 & 16 & 66.67 & 17.33 & 19.28 & 4.13 & 10.67 & 71 & 18.33 \\
\hline $\begin{array}{l}\text { Dissatisfaction in relationship with } \\
\text { children and inability to concentrate } \\
\text { on } \\
\text { their education and growth }\end{array}$ & 20.36 & 3.58 & 17 & 62.33 & 18.67 & 20.62 & 4.13 & 16.33 & 68.33 & 15.33 \\
\hline $\begin{array}{l}\text { Inability to allocate time for friends } \\
\text { and relatives and attend functions of } \\
\text { relatives and friends which affect } \\
\text { relationship with them }\end{array}$ & 22.68 & 3.83 & 12.33 & 72.67 & 15 & 22.72 & 3.95 & 15 & 69.33 & 15.67 \\
\hline
\end{tabular}

Source, Primary data, 2017 
Table 5 Perception towards impact of long working hours on performance

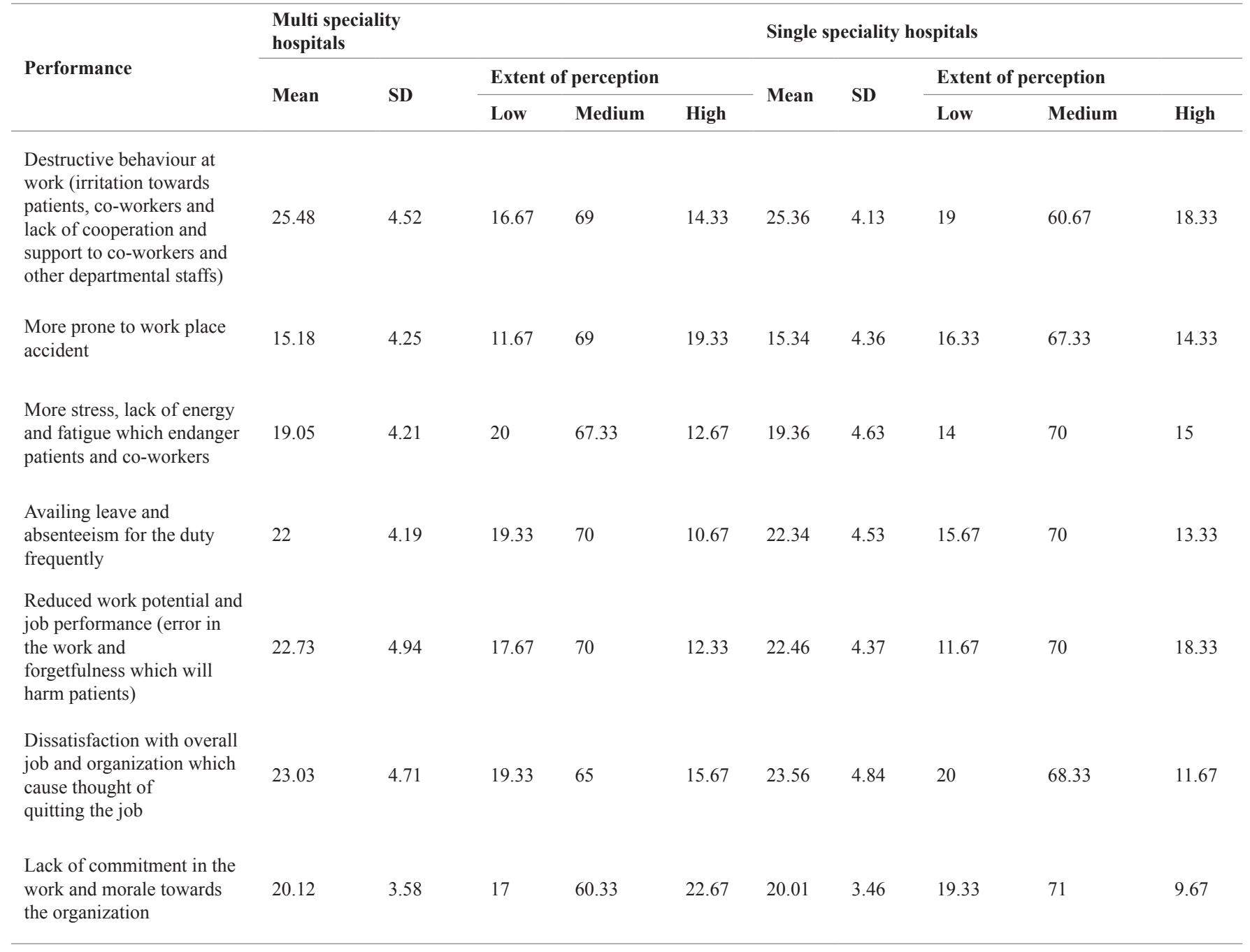

Source, Computed from primary data, 2017

\section{Suggestions and conclusion}

\section{Suggestions}

The following suggestions are given based on findings of the study.

Working hours should be regulated. It should be reduced from twelve hours to eight hours. Nurses should be educated to come to the duty on time to relieve the nurses who are currently in duty. It will avoid them to reach home lately. When the nurses leave the duty lately they may be allowed to come lately in the next day with the mutual understanding with opposite shift nurses who is her reliever. Or when nurses are happened to leave the duty lately they may be compensated for the over-time work they do. The nursing in-charge should be educated to prepare the duty schedule especially shift schedule fairly without any personal bias. They should avoid giving too long day or night shift for the nurses as it will affect their family and social life. The nurses can be allowed by nursing in charge to participate while preparing duty schedule. It will initiate them to get motivated and feel valued.
If the hospitals have the policy of long working hours (12 hours), the nurses should be allowed to take some rest in the rest room with mutual understanding of co- workers. It will help them to reenergise and refresh from long standing. Variety of rich nutrition food can be given along with tea or coffee two times per day to refresh them to comply with longer workers. Higher remuneration should be provided to compensate longer working hours. Salary deduction and discouraging speech should be avoided. Family-friendly work environment along with gym and library facilities should be established and fostered so that the nurses should feel that they are in home. Counselling and education about way of balancing home and work life should be given. Education should also reiterate importance of rest, diet food, emotional stability and ergonomics. It will make them satisfied and committed though working hours are longer than normal.

\section{Conclusion}

This survey based descriptive research undertaken in Tirunelveli city; Tamilnadu differentiated perception of nurses working in both multi-speciality and single speciality hospitals towards various factors 
associated with longer working hours and negative impacts of longer working hours on health, family life and social life. The result of the study shows that perception of nurses working in both kinds of hospitals are same towards impact of longer working hours on their health, family and social life. From equality in perception of nurses toward impact of longer working hours, it could be understood that human resource practice and policy of the organization need to be changed so that employees should work according to government rules and regulations. As satisfaction of employees and sound health are primary factors deciding their productivity and working hours are strongly associated with job satisfaction and productivity of the employees, it remains important for hospital management to look into policies related to working hours and shift schedule so that appropriate steps can be taken to regulate working hours. Moreover, hospital management should pay attention to educate them about how to manage time and balance both work and family life because family life and social life of an individual play major role in determining health and happiness of an individual that will further decide commitment and morale of the employees towards organization.

\section{Future research direction}

The present research provides multiple directions for future studies. Future research can be undertaken as a large study comprising multi-speciality hospitals and single speciality hospitals existing in entire district. Same study can be undertaken with nurses working in government hospitals and diagnostic centres separately. Comparative study can be undertaken covering nurses working in diagnostic centres and government hospitals.

\section{Acknowledgements}

None.

\section{Conflict of interest}

Author declares that there is no conflict of interest.

\section{References}

1. Rajan D. Negative impacts of long working hours: A study among nurses. Journal for Bloomers of Research. 2017;9(2):1665-1674.

2. Rosner C. Working long hours is bad for women's health. Connecticut Health I-Team. 2016.

3. Juneja H, Malhotra M. Exploring the relationship and impact of working hours on work-family conflict and social support among doctors. International journal of science and research. 2015;5(9):1583-1588.

4. Caruso CC. Negative impacts of shift work and long working hours. Journal of rehabilitation nurses. 2014;39(1):16-25.

5. Akhtar S, Kashif A, Afrif A, et al. Impact of long working hours on family well-being of corporate family. World applied sciences journal. 2012;16(9):1302-1307.

6. Rajan D, Joseph V. Stress and coping among nurses. Academicia. 2012;2(10):12-41.

7. Crew S. A qualitative study on effects of working unsocial hours. Nursing times. 2006;102(23):30-33.

8. Excessive overtime in Chinese supplier factories. Verite, USA; 2004. p. $1-30$.

9. Westen R, Matthew Gray, Lixia Qu, et al. The impact of long working hours on employed fathers and their families. Australia: Australian Institute of Family Studies. 2003. p. 1-32.

10. Qureshi MS, Munir Toor J, Zeeshan A. Impacts of late working hours on employees' performance: A case study on engineers in Telecom Company of Pakistan. Institute of Business and Management, Pakistan; 2002. p. $1-15$. 